\title{
sciendo
}

\section{URBAN FEATURES IDENTIFICATION FROM DUAL-POL SAR IMAGES WITH FILTER PROPERTIES}

\author{
AMAN KUMAR ${ }^{1}$ AND DEEPAK KUMAR ${ }^{1,2^{*}}$ \\ ${ }^{I}$ Amity Institute of Geoinformatics \& Remote Sensing (AIGIRS), \\ Amity University, Sector 125, Noida - 201313, Gautam Buddha Nagar, India \\ ${ }^{2}$ International Union for Conservation of Nature (IUCN) Commission Member, \\ Gland, Switzerland \\ *Corresponding author e-mail: deepakdeo2003@gmail.com; dkumar12@amity.edu
}

Received: $14^{\text {th }}$ August 2020, Accepted: $17^{\text {th }}$ September 2020

\begin{abstract}
There is no formal definition of feature identification but it depends on the application and context of the problem. This feature acts as primary elements for execution of several algorithms, hence feature identification is one of the significant steps for has been very interesting for several research groups. Various researchers have attempted in this regard for feature identification. The current work presents an approach for urban feature identification from satellite datasets for a detailed analysis of the features for better management of the resources. Several features based feature extraction approach has been attempted to identify the compare with statistical profiling. Microwave remote sensing is one of the significant methods of remote sensing to get the data where our optical sensors usually failed or less capable to provide accurate and timely sensed data. In today's world, active remote sensing is one of the greatest technologies which is used widely in many application areas. Synthetic aperture radar is the main object to get the actively remote sensed images. Either it's optical or microwave data, the satellite images has its many errors, in SAR, while receiving the reflected echoes from the target the trouble has occurred in the form of Speckle Noise in an image. In this paper, the focus is on about the Speckle Noise, SLC \& GRD data, the filtered images performance with Boxcar and Median filter, degraded and preserving information of an image, reduce speckle noise effect of an image.
\end{abstract}

Keywords: Synthetic Aperture Radar (SAR), Single Look Complex (SLC), Speckle-Noise, SAR

\section{INTRODUCTION}

In recent years the radar technology has proven itself for providing better data in difficult situations (Shastri et al., 2015). And many industries, organizations, institute, ministries have continued using and take advantage of this technology for the mapping, planning and much more (Tukker, 2015). The microwave remote sensing is divided into two groups (passive and active). The passive remote sensing captures the radiation which is naturally emitted from the object surface. The object emits energy sometimes in a very small amount (Li et al., 2019). On the other hand, the active system work on the presence of their source of light(transmitter) that observe the scene and used in night \& day both (Bernard et al., 2014). The sensor 
transmits a signal in the microwave bandwidth and recorded backscattered by the target towards the sensor. The time from the sending and receiving is used to calculate the distance of the target (Jian et al., 2020). And this system is called active microwave remote sensing and the most common microwave sensor is synthetic aperture radar (SAR), which provides high-resolution images (Desclée et al., 2006).

Any computational algorithm requires small features to start the algorithms to solve any simple or complex problems or issues. These features may be in the form of point, line or edge, polygon or objects. These identified objects can be used to identify the general neighbourhood operation or feature detection applied to the image. But these features are typical and can be used for localisation of features as key point features. And some others can be used as edge feature. There are several algorithms for feature detection and matching to identify the set of distinctive key points, to define a region around each key point, to extract and normalize the region content for computing a local descriptor from the normalized region.

The radar is an active remote sensing technology which itself can capture the data without the help of sun rays. The sensor illuminates the radar beam into the target then capture the reflected echoes from the surface of the target (Aher $\&$ Ph, 2014). Much error occurs due to platform, satellite, and different echoes reflected from the surface of the earth give rise to speckle noise error (Turkar et al., 2012). Or we can say Different backscattered values from the surrounding pixels in an image produce speckle noise or granular effect. Due to different phase values, the effect on an image can be constructive as well as destructive (Ullah et al., 2018). The speckle noise can reduce the quality of the image and destroy the edges information (Turkar \& Rao, 2008). For the less effect of speckle noise, in literature, there are two techniques available, the multi-look and statistical filtering (Meisen et al., 2006). Many filters came into existence with time and every filter has its advantages \& disadvantages and uses with different properties features seen on the earth surface (Romaguera et al., 2014).

The synthetic aperture radar (SAR) images used widely in many fields like hydrology, ecology, ship detection, oceanology, agriculture and mine detection and much more in remote sensing (Knoepfle et al., 1998). But the major problem in SAR images that they affected by the presence of noise in an image, for the better-quality interpretation we need to extract useful information within the image and reduce the effect of speckle noise (Turkar et al., 2012).

We have used sentinel-1 satellite which has two-part $1 \mathrm{~A}$ and $1 \mathrm{~B}$ which has a $\mathrm{C}$ band and the first-ever band used for the satellite communication (Periasamy, 2018). It can cover a large area and provide data in the worst atmospheric situations. The band having 4-8 frequency with the wavelength of 3.75-7.5 $\mu \mathrm{m}$ (Jian et al., 2020). The data usually used for the canopy study as well as for oceanic study also which can penetrate unto $3 \mathrm{~cm}$. and these two satellites reduces the receptivity cycle from 12 to 6 days.

SLC products are images which are in the slant range by azimuth imaging plane. Each image having, I \& Q values that's why it contains both amplitudes as well as phase information. The images are georeferenced using orbit $\&$ attitude data from the satellite. The SLC product spatial resolution depends on the acquisition mode. And the SLC products are generated in all acquisition modes. Sentinel satellite have different acquisition modes and interferometric is one of them/ in which satellite captures the data over the land surface. The mode itself has three sub swaths (IW1, IW2, and IW3) and the IW product is available in the slices to easily understandable and useful (Marshak et al., 2019). Each slice can be processed independently. The IW1 sub swath is close to the near range and IW3 sub swath in far range. The sub swath itself contains 10 bursts in the azimuth direction (Yang et al., 2016). 


\section{Literature Review}

The speckle noise plays an important role in image processing, especially in SAR data. And there are two techniques available for the reduction of speckle noise from an image. The first category involves multi-look processing, which merges different angle looks for a particular portion of the available azimuth spectral band, or we can say that the different polarization of the same area(Deepthi et al., 2018; Bassuk et al., 2015). The second category involves the smoothing the image using digital image processing.

The filters are available for the reduction of speckle noise from the SAR images, and every filter has its characteristics and produced different results because of different algorithms they have it (Liu et al., 2016; Veci \& March, 2015). Sometimes the result we want from the specific filter is not satisfying us due to different processing criteria. That's why they need to understand the properties of the filter has risen and here different papers results have been discussed. In the field of remote sensing, the main instrument which is used for the capture of images in worst atmospheric situations is synthetic aperture radar. Which gives high-resolution images (Blaschke et al., 2019; Ji \& Wu, 2015; Werner et al., 2014). While capturing the data due to different backscattered values from the target the speckle noise error occurs and for the better-quality interpretation, we need to extract useful information to reduce the speckle noise or enhance the image quality (Li et al., 2020; Yang et al., 2016). In this paper, the focus is more on the filtering performance and value preservation of an image. Speckle noise can degrade the quality of an image, for this reason, the comparison has taken place between the filtered and untroubled images. The speckle reduction is done on the loss of preservation information (Li et al., 2020; Mun et al., 2019; Routray et al., 2020). Based on this, equal importance has given to evaluate in details of the speckle filtering and filtering performance and preservation.

Different application areas need pre-processing of sentinel-1 SAR data, like land cover classification, vegetation monitoring, change detection and urban growth etc. and the Infor can be extracted from the covariance matrix (Betbeder et al., 2015; Canty et al., 2020). And for the generation of covariance Metrix from sentinel-1 single look complex data (SLC) different pre-processing steps are needed (Kumar, 2020; Turkar \& Rao, 2008; Maxwell \& Craig, 2008). The ESA sentinel-1 toolbox is required to generate a matrix. The paper tells about the different pre-processing steps for the different type of SAR data we acquired for our area of interest (AOI). Like single and multi-date pre-processing for the sentinel-1 data etc (Blaschke, 2010; Yang et al., 2019).

The synthetic aperture radar can achieve high resolution in range and azimuth both. Due to this reason, many application areas are working with the microwave data like hydrology, geology etc. but the problem came while the speckle noise occurs on an image due to unwanted back values from the target (Gibril et al., 2017). The SAR raw data contains the granular appearance in images. For the reduction and removal of this granular effect from an image various low and high pass filtered are used. The speckle noise plays an important role in image processing (Liu et al., 2016). That's why the statistical properties of the speckle need to be analysed for the reduction of granular appearance. In this paper for the understanding of the speckle-noise effect, the compound model used for the separation out of speckle and texture from the SAR raw data (Blaschke et al., 2019; Canty et al., 2020). There are different filters use for different outputs like lee, frost and Kuan filters are used for the extracted texture.

The development of local adaptive median filter uses stats for the speckle and replace the values with the local median values. Studied Found that the median filter sometimes outperformed to make a balance between speckle-noise reduction and preservation of information into an image. There are different filters available for the speckle but simplest 
there are mean and median filter, in which the central value is replaced by the mean and median, respectively (Roy et al., 2016). Mean and median both are low-pass filters, they perform well in smoothing the image but create problem in the finer edges detail with speckle noise. But the median filter is much better than the mean because it can remove the pulse and spike noise and preserve the information between two different features. But it's not capable to store or preserve info pixel by pixel of the feature (Marpu et al., 2010). When the filters are applied in SAR data sets, the success reason is due to the non-adaptive filter properties, because they cannot sense particular speckle of feature properties of the image. And the nature of speckle-noise relates the amount of noise to signal intensity (Martí-Vidal et al., 2016).

Boxcar filter is also known as multi look filter and is based on MLE covariance Metrix C. the filter performs all over the image and replaces the central value with the average of the selected samples given by the window (Jian et al., 2020). Technically boxcar is a low-pass filter which enhances the radiometric resolution of an image. But due to speckle reduction, at the expense of spatial resolution is decreasing. The better result comes with the $7 * 7$ window size, but the $3 * 3$ window gives better result in the spatial resolution manner, but contribute less in the suppression of speckle noise. The more the window size the more the speckle suppression perform, like the result with $9 * 9$ window shows very less speckle but it can decrease the spatial resolution (Kumar \& Shekhar, 2016; Loukanov et al., 2020). The speckle noise reduction enhanced the quality of radar coherent image. The radar images required the reduction of speckle noise before using the SAR imageries (Li et al., 2020). However, most researcher already took care of reduction techniques or methods but there is no single technique or method available for the all SAR data according to the feature which can preserve the edge detail without harming spatial resolution. Paper discussed different speckle-noise reduction filters, and the results shown by the tables, figures and output images (Singh et al., 2020).

As we know that the granular effect or salt pepper effect on an image can reduce the interpretability capacity of an image, it affects many application areas, and the medical sector is one of them, the ultrasound images also corrupted because of speckle-noise as granular noise. It is a very important and crucial task to deal with it while working in the medical sector. Many researchers use different types of filters and presented their work on it. And analysed the statistics for that. This paper also took care of that part. Filtering and preservation detail are the most two important key contexts in speckle reduction of SAR images. The balance is required between speckle-noise reduction and detail preservation for many different applications (Dass \& Yadav, 2020). This paper presents the quantitative and qualitative of both aspects and include texture preservation and a visual assessment to evaluate the filter performance. Different data were used here one is JERS-1 SAR data and SIR-C/X SAR data with different polarization. And the results proposed that in context to preserve the edges LEE, frost and Lee sigma \& Gamma filters are best because they can maintain a balance between speckle reduction and preservation of detail in much application areas (Jian et al., 2020; Lee et al., 2016). The paper discusses the smoothing algorithm, the filter is based on the sigma of Gaussian distribution which helps to smooth the speckle noise by averaging the neighbourhood pixels to the centre pixel. The algorithms are analysed with other filtering algorithms by their ability to preserve details, edges, shapes, etc. and the results show that the sigma filter is the most effective and it would be extended to $3 \mathrm{D}$ smoothing the image (Guo et al., 2018; Li et al., 2020). The detailed algorithms concept of each filter is discussed in this paper, which also makes a highlight for the better granular noise reduction to solve the problem related with the SAR datasets used for the wide applications areas (Ghorbanian et al., 2020). The comparisons for each filter have been 
discussed to know the effectiveness of the filter properties and the reduction rate for the edges, lines and point. Additionally, the complexity of the statistics is also compared for each filter. The results are clearly showing the selection criteria of filter for the required SAR datasets and feature. This paper deals with the Radarset- 2 images for the speckle suppression with the Lee, Lee-sigma, Frost and Gamma-map, in general, the mean \& median filters are also included (Dass \& Yadav, 2020). All filters are analysed and prove the result that some filters perform well to reduce the effect of granular noise and preserve the details of the edge (Liu et al., 2019; Jian et al., 2020).

Filters: To reduce errors in the radar images. There are two types of techniques used. First is multi-look (overlapping the same area images captured by different angle) which is used during the data acquisition and next one is the use of different filters which we can use during or after the data acquisition. When we talking about the reduction of speckle noise filters, there are different types of filters are used as the requirement of reduction of speckle-noise with the fine details. In a very simple way, we can say that speckle filtering is the movement of the kernel for each pixel in the image and applying mathematical calculation to reduce the pixels noise under the kernel. The kernel is moved from pixel to pixel and covers the whole area of the image. This filter smoothing the image and reduce the speckle effect.

\section{Scalar Filters}

Based on the ratio of local statistics and use for the reduction of speckle noise mainly in the homogeneous regions in an image. Mean and median are the types of scalar filters.

\section{Mean Filter}

Invented by pomalaza-Raez in 1984, is a basic filter which is used earlier more and especially when we don't need good spatial resolution because these filters can reduce the spatial resolution. It is average the centre pixels by all pixels. This filter can blur the image so it's a very least satisfactory filter.

\section{Median Filter}

Invented by pitas in 1990, Median filter is also the basic filter but improved than a mean filter. Here, the centre pixel is average by the median of all pixel and it takes more time than a mean filter for calculations. The blurring of the image is less here than mean filter and also preserve edges more than a mean filter.

\section{Adaptive Filters}

To preserve the edges information and reduce the effect of speckle-noise various adaptive filters have discussed in this paper. Use various window size to reduce the speckle effect. Generally, lower the window size gives better edge preservation and higher the window size degraded the edges.

\section{Lee Sigma and Lee Filter}

Lee filter is developed by Jong-Sen-Lee in 1982 these filters are based on the Gaussian distribution and are work on the statistical distribution of the image. When we applying these filters, we get some statistics like Mean, Median, Standard Deviation. These are some methods from them we know how much reduction of speckle-noise take place. The kernel size also matters for the reduction of speckle noise and its varying from $5 * 5$ to $17 * 17$ in snap software. Kernel size will be in odd numbers always.

\section{Frost Filter}

Invented by frost in 1982, frost filter works on the average of a centre pixel by the sum of neighborhood pixels within the kernel. But it preserves edged information more while suppression of noise. 


\section{Gamma-Map Filter}

Proposed by Lopes in 1993, Gamma filters are used when we want to remove high-frequency noise. Better than the Lee and Frost filter. Usually, a low-pass filter is used for speckle noise reduction. They can remove the speckle noise but the preservation of edges details sometimes degraded that's why we use gamma filter because it can preserve the details of the edge also with the smoothing of image.

Level-1 Ground Range Detected (GRD) products consist of SAR data which has been detected and multi-looked and projected to ground range using an Earth ellipsoid model. Phase information we can't get it because it is lost and the resulting product is almost square spatial resolution pixels and square pixel spacing with is reduced the speckle at the cost of worse spatial resolution. GRD products can be available in three forms:

1. Full Resolution

2. High Resolution

3. Medium Resolution

Resolution is depending on the multi look and Level-1 GRD products are available in MR and HR for IW and EW modes, MR for WV mode and MR, HR and FR for SM mode. (ESA earth observation). The sentinel-1 toolbox is the part of a SNAP software. Which is used for the remote sensing purpose. The SNAP software support reading, processing, displaying and stored the data in the required format. Various types of satellite remote sensing data can be performed in a SNAP software like RADARSAT, ENVISAT, and SENTINEL etc. The software comes with the other toolboxes like sentinel-2, sentinel-3 etc.

\section{MATERIALS AND METHODS}

\section{Study Area}

The research work is tried at Lucknow district of Uttar Pradesh state, India. The city of Lucknow ranks as the twelfth populated urban area with an aerial extent of around $2,528 \mathrm{~km}^{2}$ with an elevation of 123 meters above mean sea level. The city gets water supply through the river Gomti River network and the same river subdivides the complete city region into two regions including Trans Gomti and cis-Gomti region. Figure 1 illustrates the location of the study area. 
Fig. 1: Location of Pilot Study Area
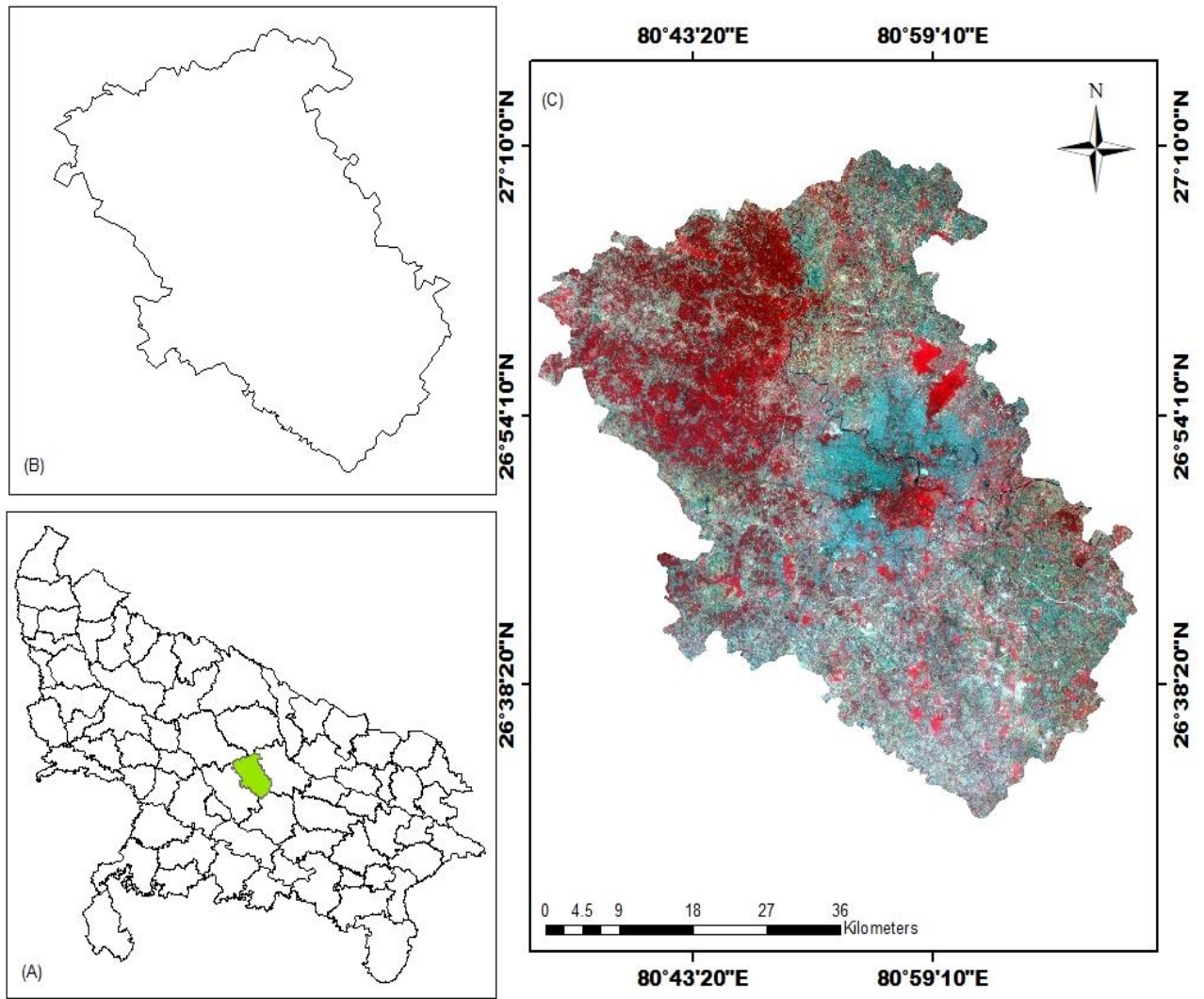

\section{Datasets Used}

The work uses the satellite datasets of Sentinel-1. This satellite system consists of 2 satellites, namely sentinel 1A and sentinel 1B. Each of them operates in C-band SAR having spatial resolution of $5 \mathrm{~m}$ with swath of $400 \mathrm{~km}$. The satellite have a 6-day repeat cycle at an altitude of $693 \mathrm{~km}$. These satellite provides Level-1 Ground Range Detected (GRD) SAR data products projected to ground range using an Earth ellipsoid model. There is no Phase information available with GRD products and these are available in three modes (a) Full Resolution, (b) High Resolution, and (c) Medium Resolution. There is the following sequence of steps for downloading the datasets.

(a) Visit official website of vertex Alaska Satellite Facility (ASF's) data portal.

(b) Sign up or sign in to the existing or new account

(c) Select the area of interest.

(d) Provide the required parameters for data download.

(e) Click on the search button.

(f) List of images will be displayed on the left side of the panel.

(g) Select the required image to be downloaded and click on the image as per the requirement.

(h) Download the image and pre-process it before any application. 
The downloaded datasets consists of *.zip file and it consists of sub-files namely METADATA, VECTOR DATA, TIE-POINT, QUICKLOOK AND BAND. The detailed specification of the metadata being provided with downloaded file is summarised in table 1 .

Table 1: Metadata details of downloaded GRD SAR datasets

\begin{tabular}{lll}
\hline \multicolumn{1}{c}{ PRODUCT TYPE } & \multicolumn{1}{c}{ GRD } & \multicolumn{1}{c}{ MODE } \\
\hline MISSION & SENTINEL-1A & SATELLITE MISSION \\
ACQUISITION MODE & IW & ACQUISITION MODE \\
ANTENNA POINTING & RIGHT & RIGHT OR LEFT FACING \\
ORBIT CYCLE & 173 & CYCLE \\
INCIDENCE NEAR & 30.76721279098475 & DEG \\
INCIDENCE FAR & 46.21031450776563 & DEG \\
PASS & ASCENDING & ASCENDING OR DESCENDING \\
RANGE LOOKS & 5.0 & \\
RANGE SPACING & 10.0 & RANGE SAMPLE SPACING \\
AZIMUTH SPACING & 10.0 & AZIMUTH SAMPLE SPACING \\
RADAR FREQUENCY & 5405.000454334349 & RADAR FREQUENCY \\
\hline
\end{tabular}

\section{Methodology}

This paper deals with the sentinel images for the speckle suppression with the Lee, Lee-sigma, Frost and Gamma-map, in general, the mean \& median filters. All filters are analysed to understand the working of the filters and to reduce the effect of granular noise to preserve the details about the edge information. The comprehensive methodology for evaluating the satellite data has been illustrated in figure 2. These metholdogy consist of various operations like SUBSET, SPLIT, MERGE, BACKGROUND NORMALISATION, COREGISTRATION ETC. Thse are useful in preprocessing of the downlaodd datsets and to derive the requiste information the image. 
Fig. 2: Flowchart for SAR datasets Pre-Processing

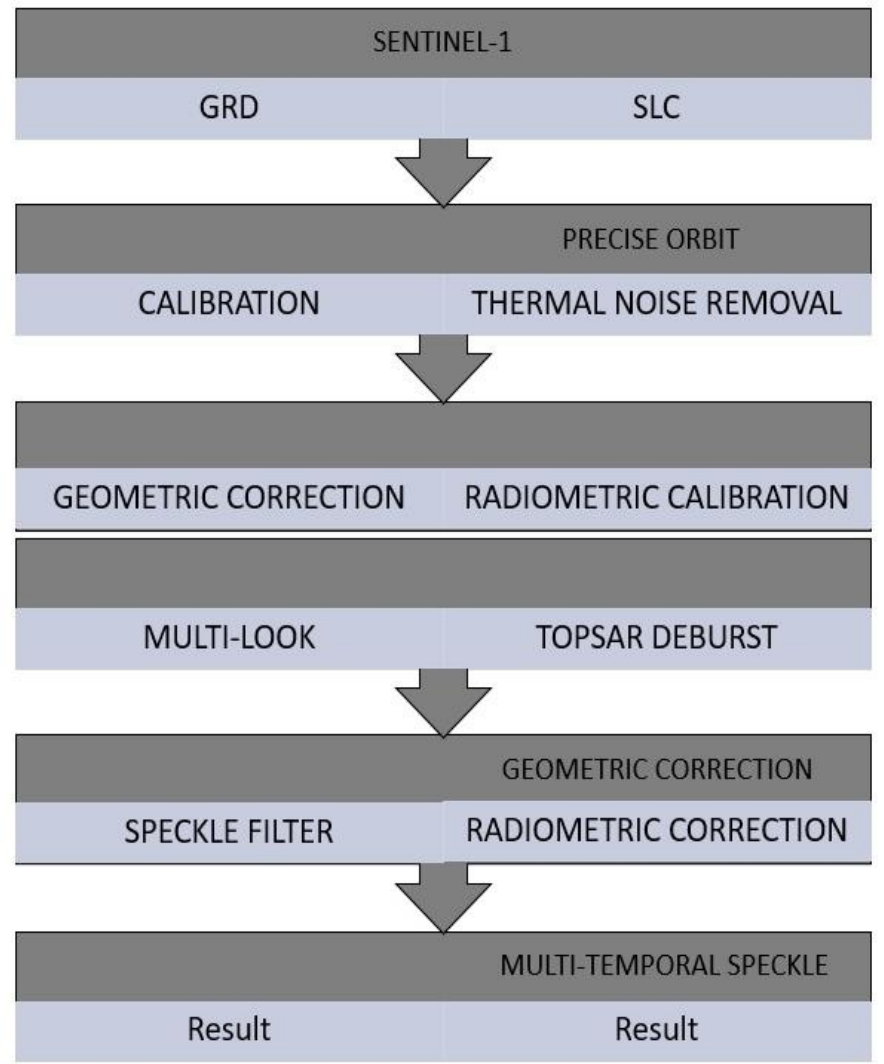

\section{Pre-processing Sequence of SNAP Toolbox}

The sequence of steps is required to process the single look complex (SLC) datasets.

1. Open the snap software and load the downloaded *.zip file (as raw file). There is no requirement to unzip the file. As the software automatically read and accesses the file without unzipping.

2. Apply the Precise Orbit File: The first process starts with the application of precise orbit file. During the acquisition of sentinel-1 data, the satellite position is recorded by the GNSS. And the orbit information is generated by the on-board navigation. Later on, the orbit positions are refined through the POD service (precise orbit determination). Always it is important to use the most accurate orbit information because it is highly influenced by the pre-processing of the images. Especially in the geo-referencing of the data.

3. Apply Thermal Noise Correction: - is randomly appearing over the image. And is caused by the receiver signal power. It is unnoticeable therefor the impact factor is high. Degrades data quality.

4. Perform Radiometric Calibration: It is the process of converting DN values to equivalent backscatter values. Radiometric calibration is required due to the radiometric correction. For the comparison of different sensors or different dates or even the same sensor for a different date or acquisition modes are is not possible.

Follow: RADAR $\rightarrow$ RADIOMETRIC $\rightarrow$ CALIBRATE 
5. Perform TOPSAR Deburst: Sentinel-1 image is acquired in IW or EW mode (one image per swath and polarization). IW products are made up of 3 swaths; it means three images for single-polarization and six images for dual-polarization. EW products are made up of 5 swaths; it means five images for single-polarization and ten images for dual-polarization. Different bursts are available in one single image and they are separated by black demarcation.

Follow: RADAR $\rightarrow$ SENTINEL-1 TOPS $\rightarrow$ S1 $\rightarrow$ TOPS DEBURST

6. Apply Geometric Correction: This process convert's slant range geometry into ground range. While acquiring the data different errors may have errors like foreshortening, layover and shadow effects. The best way to correct them all is the range-Doppler approach.

\section{Follow: RADAR $\rightarrow$ GEOMETRIC $\rightarrow$ TERRAIN CORRECTION $\rightarrow$ RANGE DOPPLER TERRAIN CORRECTION}

7. Apply Backscatter Normalisation: The conversion of backscattered values to sigma naught equivalent. Due to terrain variation, we have to consider the local incidence angle, not the ellipsoid one. The backscattered values is not depending on the area itself; the incidence angle is also an important factor for the number of backscattered values. Higher backscattered values come from the small incidence angle and higher the incidence angle means smaller the backscattered values. Incidence angle variation is not occurring only within the image but also different images from different sensors or different modes. And the same sensors with different acquisition modes. Sentinel $1 \mathrm{~A}$ and $1 \mathrm{~B}$ time is acquired on different orbit or track therefor this technique are used to minimize the backscattered variation caused by the incidence angle.

\section{Follow: RADAR $\rightarrow$ GEOMETRIC $\rightarrow$ TERRAIN CORRECTION $\rightarrow$ RANGE DOPPLER TERRAIN CORRECTION}

a. Co-Registration: This method is used for the time series images to fit in the same grid.

b. Multi-Temporal Speckle Filter: Due to the different echoes from the target product the speckle noise is generated. It is shown on an image like salt and paper effect. The speckle noise degrades the quality of the image and hard to interpret. There are different filters available for the reduction of speckle noise from the image and multi-temporal speckle filter results show better reduction with the high temporal resolution.For the GRD data, there are only a few steps which were a part of preprocessing steps of SLC data and I have been already discussed above. Radiometric calibration to multi-look to speckle filtering and the geometric correction.

\section{OPTIONAL TOOLS}

- SUBSET: - as the name itself showing the meaning, it helps to reduce the size of an image, or we can say that with the help of subset tool we can get our area of interest (AOI) from the raw data.

\section{RASTER - SUBSET}

- TOPS SPLIT: - with the help of a split we can select burst into a separated product RASTER - SENTINEL 1 TOPS - S 1 TOPS SPLIT

- TOPS MERGE: - tops merge helps to merge bursts products of different sub swaths. 
RESULTS AND ANALYSIS

Pre-processing of SAR Image

RASTER - SENTINEL 1 TOPS - S 1 TOPSAR-Deburst Operator: This process mainly converts DN values to radar backscatter. Because sentinel-1 products are not radiometric corrected by default. So, we must do this process otherwise comparison of SAR images from different sensors or different acquisition dates is not possible.

Fig. 3: Image after TOPSAR-Deburst Operator

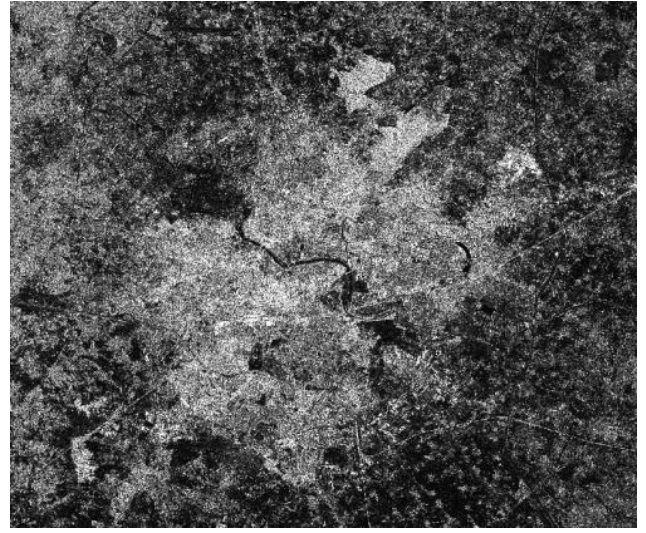

(a) VH Polarisation

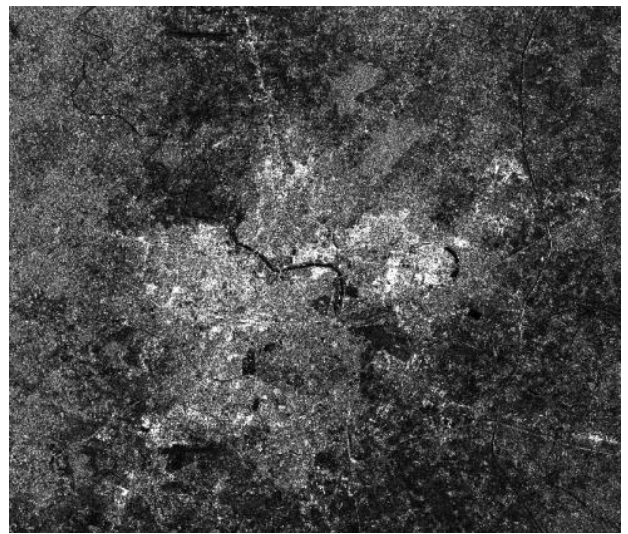

(b) VV Polarisation

Table 2: Summary statistics of SLC Image after TOPSAR-Deburst operator

\begin{tabular}{lrr}
\hline \multicolumn{1}{c}{ STATISTICS } & \multicolumn{1}{c}{ VH } & \multicolumn{1}{c}{ VV } \\
\hline MINIMUM & & 0.0 \\
MAXIMUM & 255.0 & 255.0 \\
MEAN & 82.11888420312707 & 73.1270514848022 \\
MEDIAN & 70.96618878408533 & 61.24108215984811 \\
SIGMA & 59.542500000000004 & 54.4425 \\
COEF VARIATION & 1.504664433970355 & 1.6485918025002735 \\
\hline
\end{tabular}

Table 3: Summary statistics of GRD image after median filter operator

\begin{tabular}{lrr}
\hline \multicolumn{1}{c}{ STATISTICS } & \multicolumn{1}{c}{ VH } & \multicolumn{1}{c}{ VV } \\
\hline MINIMUM & 0.003847580635920167 & 0.005751345306634903 \\
MAXIMUM & 4.631367206573486 & 13.03277587890625 \\
MEAN & 0.03324338421221616 & 0.13040955607531166 \\
MEDIAN & 0.026985178765607996 & 0.10996754157543183 \\
SIGMA & 0.03512904350601524 & 0.14499217431969738 \\
COEF VARIATION & 1.0567206462139307 & 1.1118193876168772 \\
\hline
\end{tabular}


Fig. 4: Ground Range Detection Images

\section{VH Polarisation}

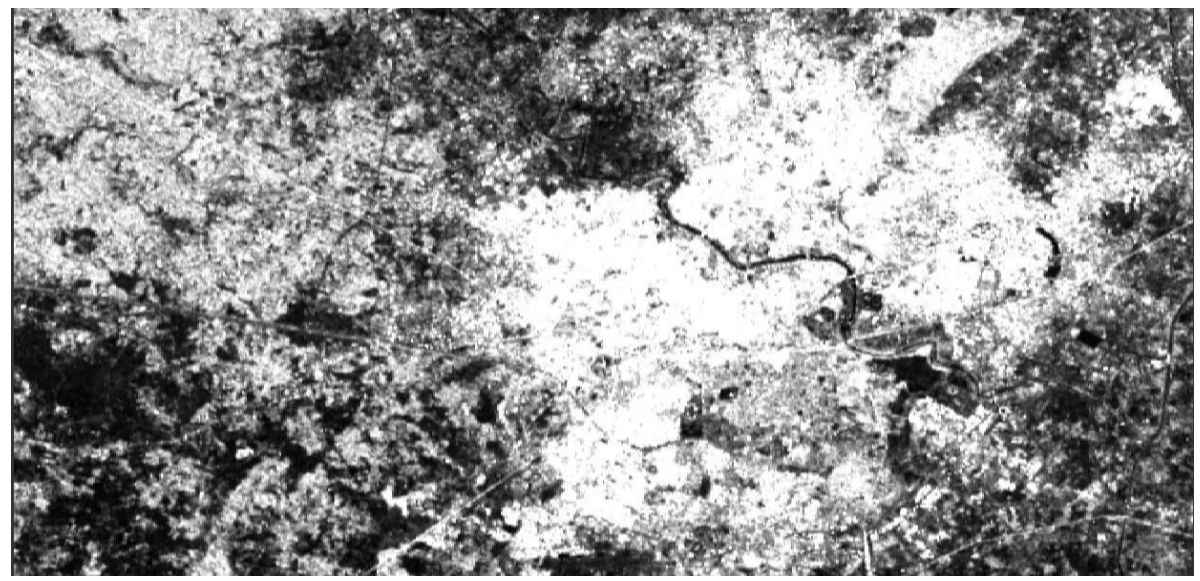

\section{VV Polarisation}

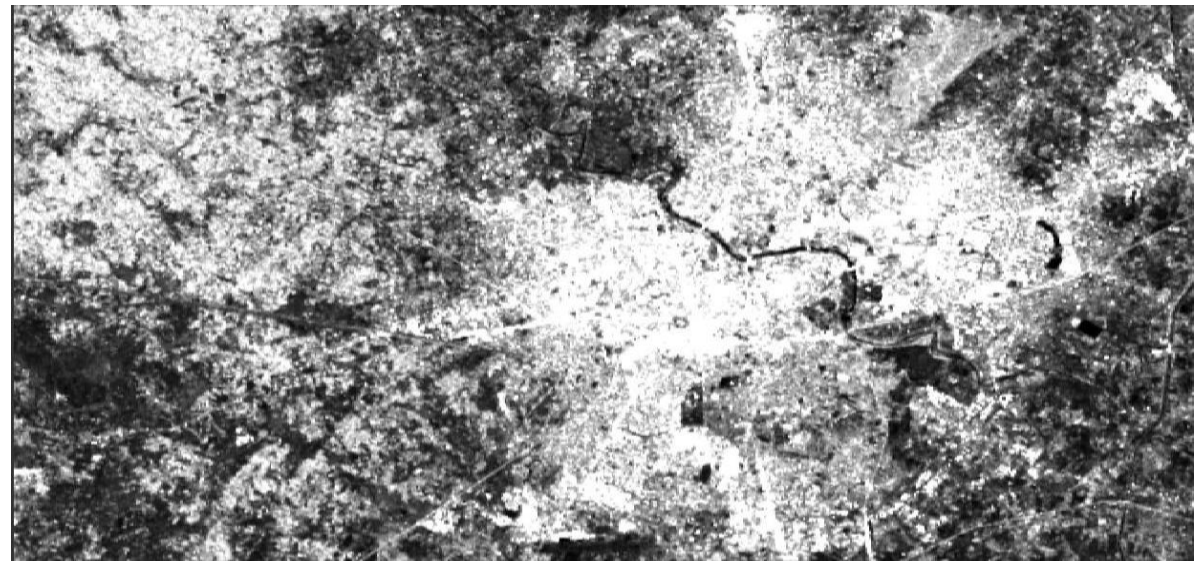




\section{RGB Composite}

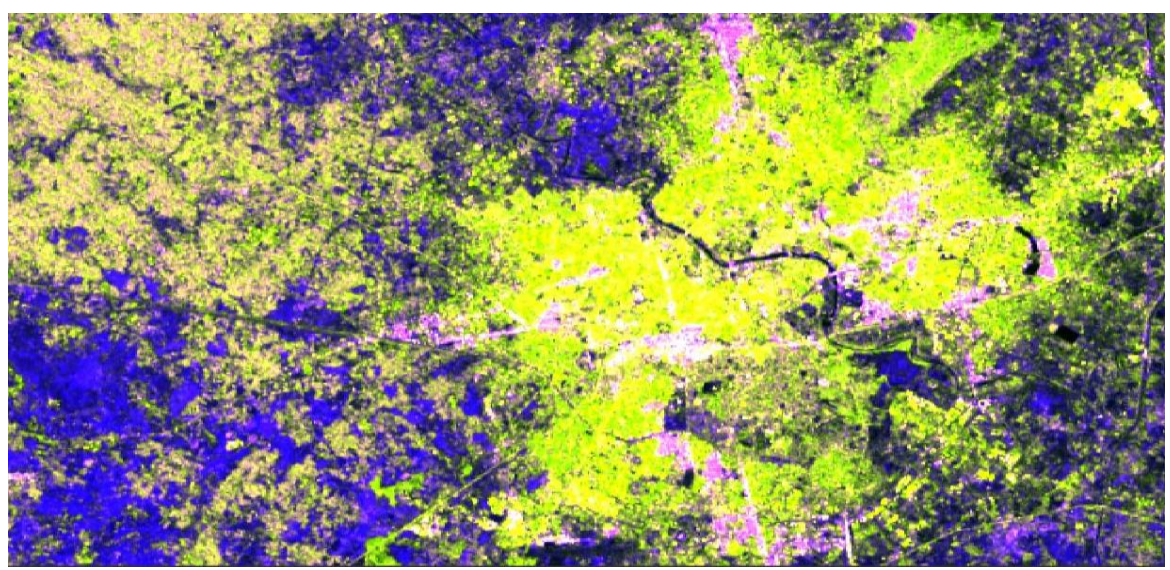

Table 4: Summary statistics of each feature

\begin{tabular}{lcc}
\hline \multicolumn{1}{c}{ POLARISATION SPECIFICATION } & VH & VV \\
\hline RIVER & -21.34 & -17.34 \\
SEWAGE TREATMENT PLANT & -23.17 & -19.19 \\
LAKE & -22.31 & -17.64 \\
BRIDGE & -9.4 & 0.7 \\
ROAD & -17.98 & -4.0 \\
VEGETATION & -12.59 & -8.59 \\
AGRICULTURE & -21.51 & -14.73 \\
PARK & -21.22 & -13.60 \\
SETTLEMENT & -10.80 & -6.17 \\
BARREN LAND & -21.75 & -17.38 \\
RAILWAY STATION & -7.20 & 0.78 \\
\hline
\end{tabular}

Fig. 5:Processed RGB composite GRD Image

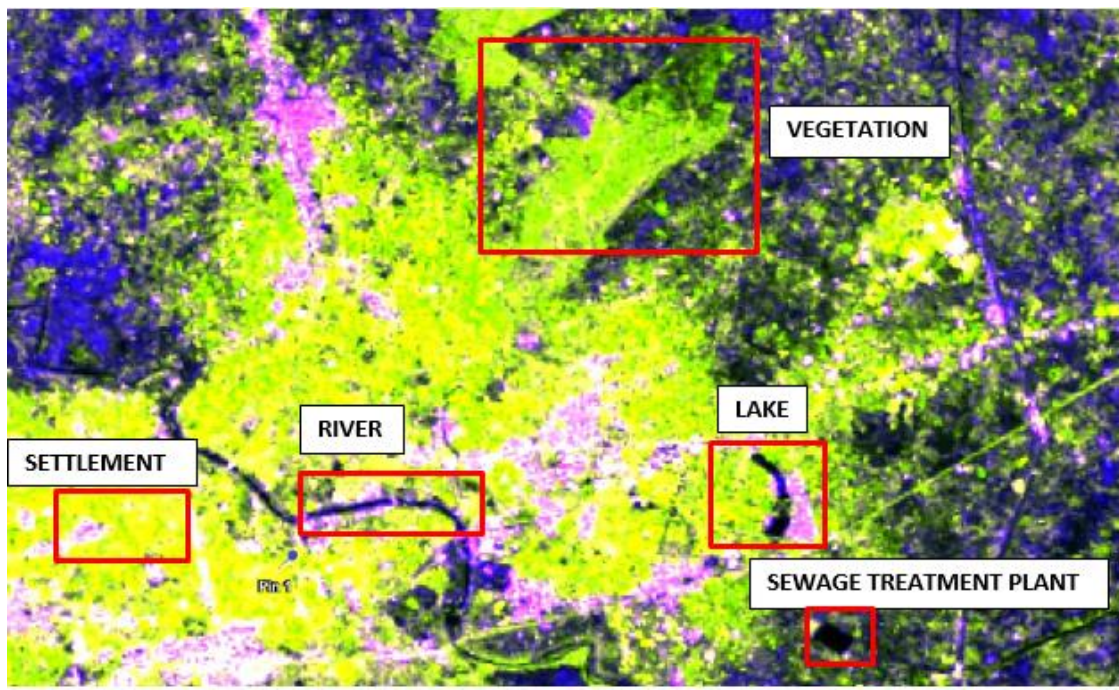


Kumar A., Kumar D.: Urban Feature Identification from Dual-Pol SAR Images with Filter Properties

Table 5: Summary statistics of vegetation features

\begin{tabular}{ll}
\hline Minimum: & 9.0 \\
\hline Maximum: & 255.0 \\
\hline Mean: & 157.76910604056343 \\
\hline Sigma: & 55.71335069110299 \\
\hline Median: & 169.4265 \\
\hline Coeff. Variation: & 0.5780497559903859 \\
\hline
\end{tabular}

Fig. 6: RGB composite GRD Image of vegetation features

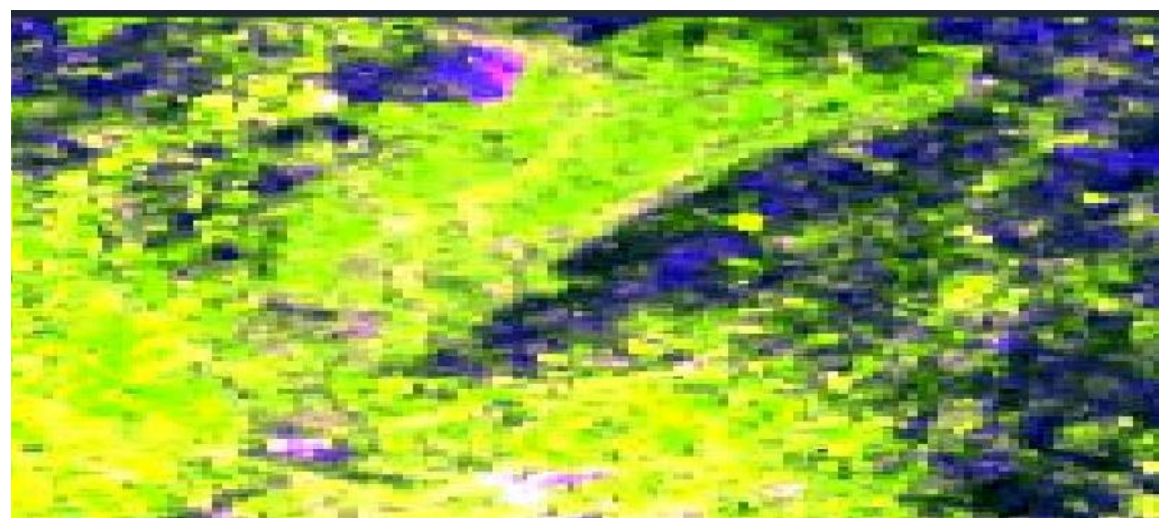

Table 6: Summary statistics of water (river) features

\begin{tabular}{ll}
\hline Minimum: & 0.0 \\
\hline Maximum: & 255.0 \\
\hline Mean: & 61.784501763665354 \\
\hline Sigma: & 51.07295190157614 \\
\hline Median: & 52.608000000000004 \\
\hline Coeff. Variation: & 1.8007906364425679 \\
\hline
\end{tabular}

Fig. 7: RGB composite GRD Image of water (river) features

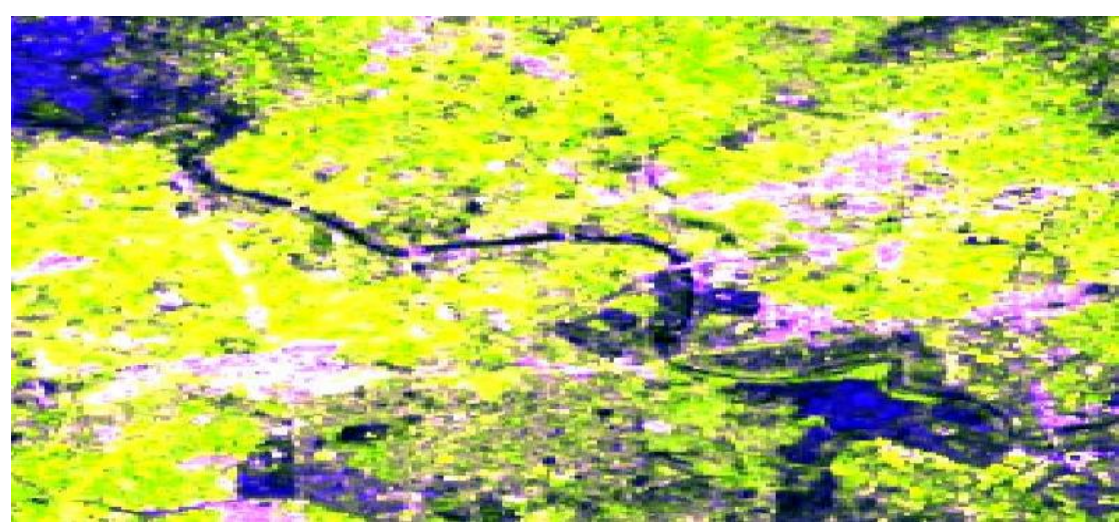


Table 7: Summary statistics of water (lake) features

\begin{tabular}{ll}
\hline Minimum: & 0.0 \\
\hline Maximum: & 255.0 \\
\hline Mean: & 42.315951278660414 \\
\hline Sigma: & 79.8258979630508 \\
\hline Median: & 0.512 \\
\hline Coeff. Variation: & 2.322577779271916 \\
\hline
\end{tabular}

Fig. 8: RGB composite GRD Image of water (lake) features

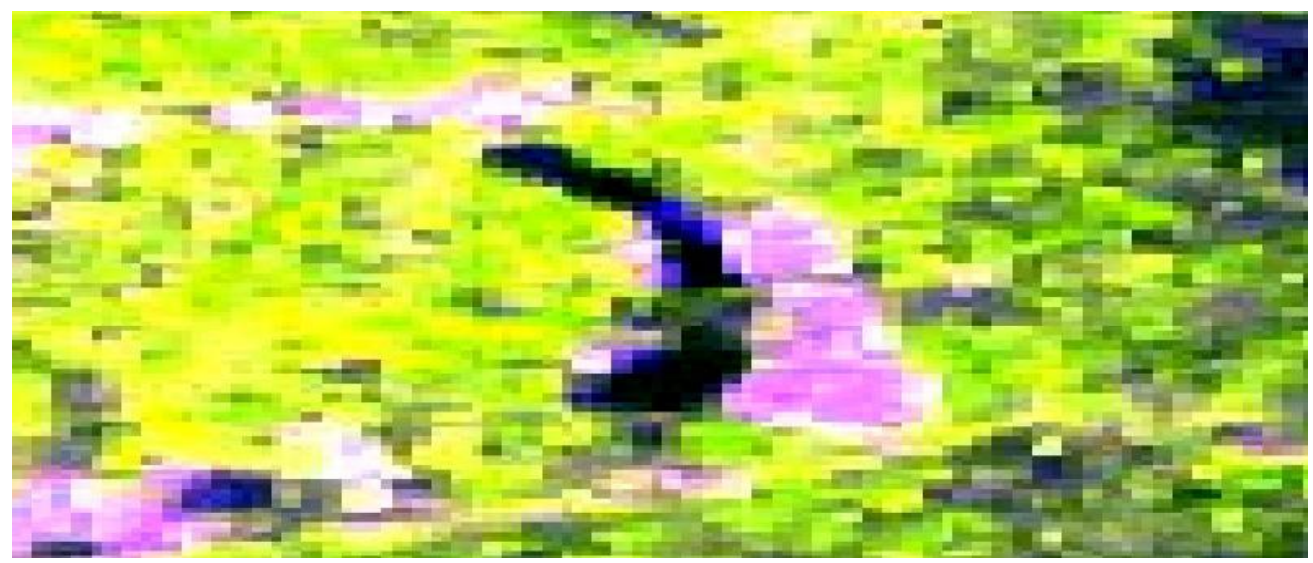

Table 8: Summary statistics of water (Sewage Treatment Plant) features

\begin{tabular}{ll}
\hline Minimum: & 0.0 \\
\hline Maximum: & 188.0 \\
\hline Mean: & 7.817800925925924 \\
\hline Sigma: & 18.703234712068035 \\
\hline Median: & 0.0945 \\
\hline Coeff. Variation: & 3.4038729223314155 \\
\hline
\end{tabular}

Fig. 9: RGB composite GRD Image of water (Sewage Treatment Plant) features

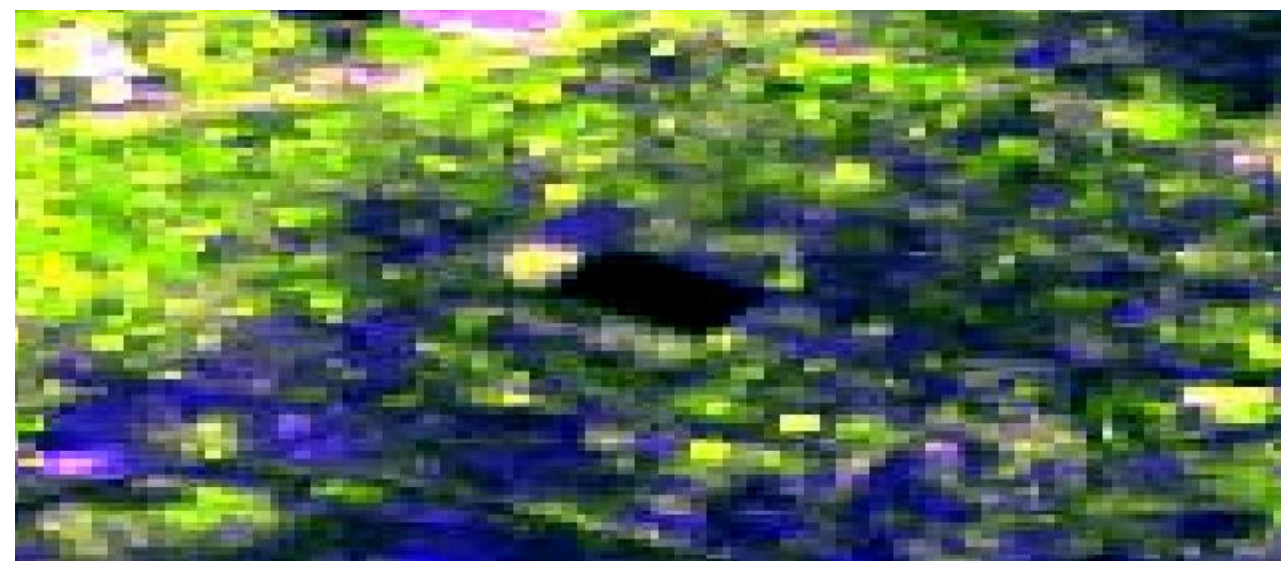


Kumar A., Kumar D.: Urban Feature Identification from Dual-Pol SAR Images with Filter Properties

Table 9: Summary statistics of settlement features

\begin{tabular}{ll}
\hline Minimum: & 248.0 \\
\hline Maximum: & 255.0 \\
\hline Mean: & 254.8576488095195 \\
\hline Sigma: & 0.39580274397258125 \\
\hline Median: & 254.50400000000002 \\
\hline Coeff. Variation: & 0.003097678403225489 \\
\hline
\end{tabular}

Fig. 10: RGB composite GRD Image of settlement features

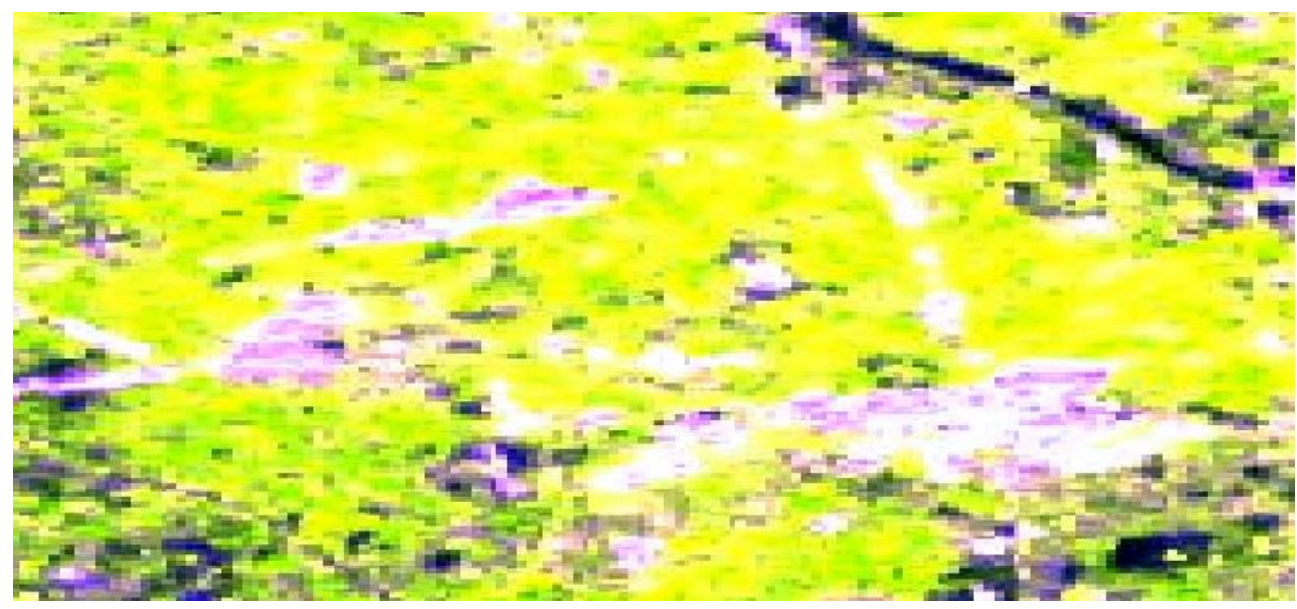

Fig. 11: RGB composite GRD Image with highlighted urban features

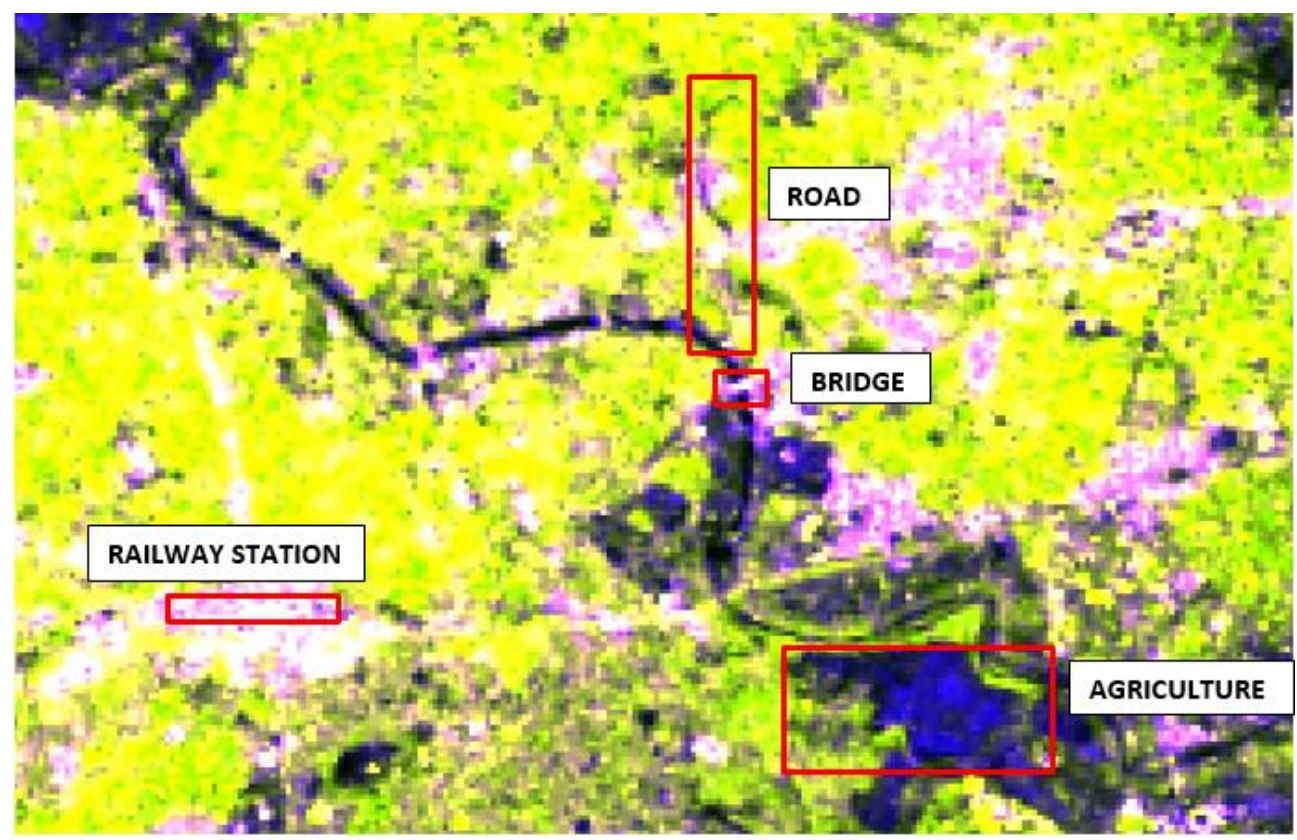


Table 10: Summary statistics with median and boxcar filters

\begin{tabular}{lll}
\hline STATISTICS & MEDIAN FILTER & BOXCAR FILTER \\
\hline MINIMUM & 0.003926648758351803 & 0.004040635656565428 \\
MAXIMUM & 13.03277587890625 & 16.462860107421875 \\
MEAN & 0.09316526063426248 & 0.09366717806620173 \\
MEDIAN & 0.08209974413923919 & 0.06987591354362667 \\
SIGMA & 0.06559885342771993 & 0.07175374073071189 \\
COEF VARIATION & 0.7040 & 0.7660498360157526 \\
\hline
\end{tabular}

Table 11: Summary statistics of park features

\begin{tabular}{ll}
\hline Minimum: & 6.0 \\
\hline Maximum: & 255.0 \\
\hline Mean: & 70.04962301587244 \\
\hline Sigma: & 52.647101945322554 \\
\hline Median: & 54.625 \\
\hline Coeff. Variation: & 1.8678926255957058 \\
\hline
\end{tabular}

Table 12: Summary statistics of man-made feature (railway station)

\begin{tabular}{ll}
\hline Minimum: & 229.0 \\
\hline Maximum: & 255.0 \\
\hline Mean: & 254.8754949294482 \\
\hline Sigma: & 0.7744078265325501 \\
\hline Median: & 254.488 \\
\hline Coeff. Variation: & 0.005963693496387255 \\
\hline
\end{tabular}

Fig. 12: RGB composite GRD Image with highlighted man-made (railway station) feature

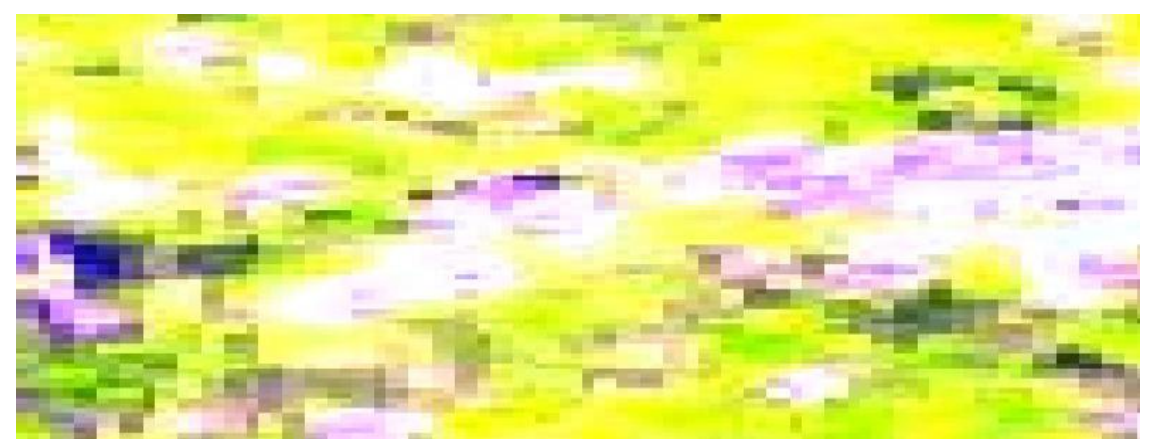

Table 13: summary statistics of man-made feature (bridge)

\begin{tabular}{ll}
\hline Minimum: & 90.0 \\
\hline Maximum: & 255.0 \\
\hline Mean: & 254.45311838624175 \\
\hline Sigma: & 7.641892661706978 \\
\hline Median: & 254.423 \\
\hline Coeff. Variation: & 0.04539589273707176 \\
\hline
\end{tabular}


Kumar A., Kumar D.: Urban Feature Identification from Dual-Pol SAR Images with Filter Properties

Fig. 13: RGB composite GRD Image with highlighted man-made (bridge) features

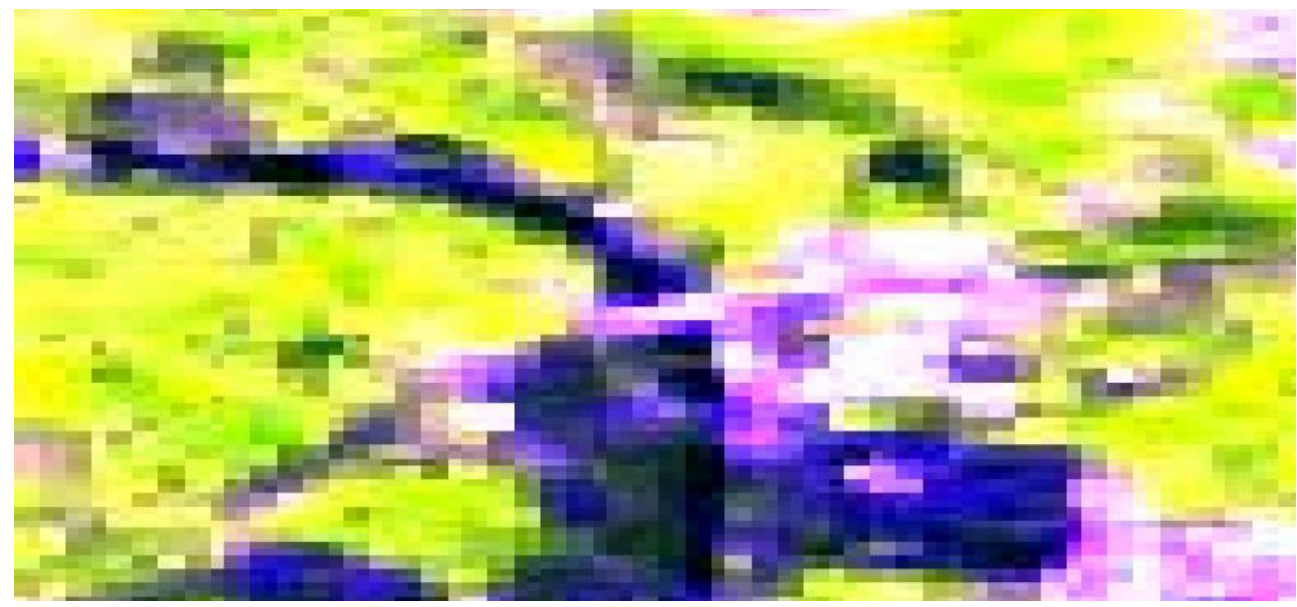

Table 14: Summary statistics of agriculture feature

\begin{tabular}{ll}
\hline Minimum: & 11.0 \\
\hline Maximum: & 179.0 \\
\hline Mean: & 38.17536375661376 \\
\hline Sigma: & 16.290093827482917 \\
\hline Median: & 33.5615 \\
\hline Coeff. Variation: & 1.23794781427987 \\
\hline
\end{tabular}

Fig. 14: RGB composite GRD Image with highlighted agriculture feature

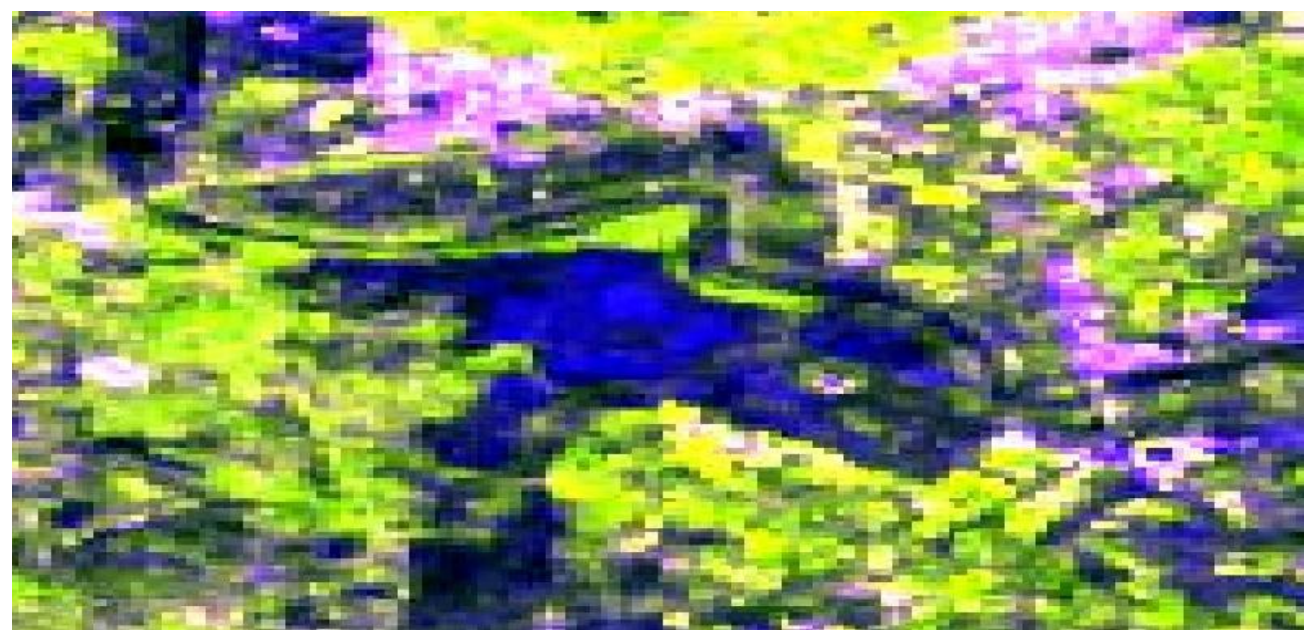


Table 15: Summary statistics of road

\begin{tabular}{ll}
\hline Minimum: & 154.0 \\
\hline Maximum: & 255.0 \\
\hline Mean: & 251.94367063492962 \\
\hline Sigma: & 15.6592238127871 \\
\hline Median: & 254.52100000000002 \\
\hline Coeff. Variation: & 0.10332104834584968 \\
\hline
\end{tabular}

Table 16: Summary statistics of $\mathrm{dB}$ values after application of boxcar filter on GRD image

\begin{tabular}{lll}
\hline \multicolumn{1}{c}{ STATISTICS } & \multicolumn{1}{c}{ VH } & \multicolumn{1}{c}{ VV } \\
\hline MINIMUM & 0.0030913162045180798 & 0.006060429848730564 \\
MAXIMUM & 7.771010875701904 & 16.462860107421875 \\
MEAN & 0.032790227085256134 & 0.13334064151363573 \\
MEDIAN & 0.02639507488301024 & 0.10480122791416943 \\
SIGMA & 0.04065090350567952 & 0.16382081400062232 \\
COEF VARIATION & 1.2397236105979912 & 1.2285862017554385 \\
\hline
\end{tabular}

Fig. 16: Image after application of boxcar filter on GRD image Ground Range

(a) VH Polarisation

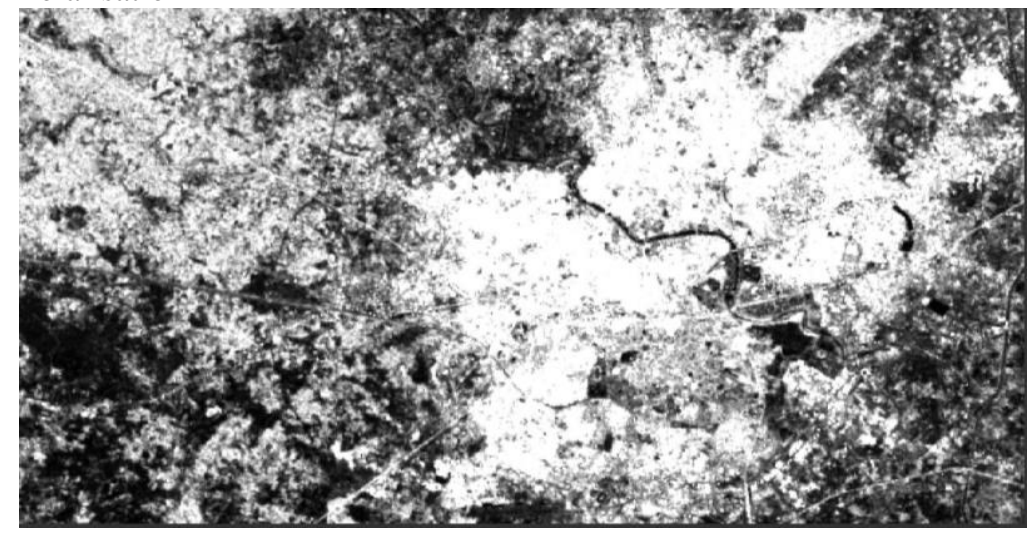

(b) VV Polarisation

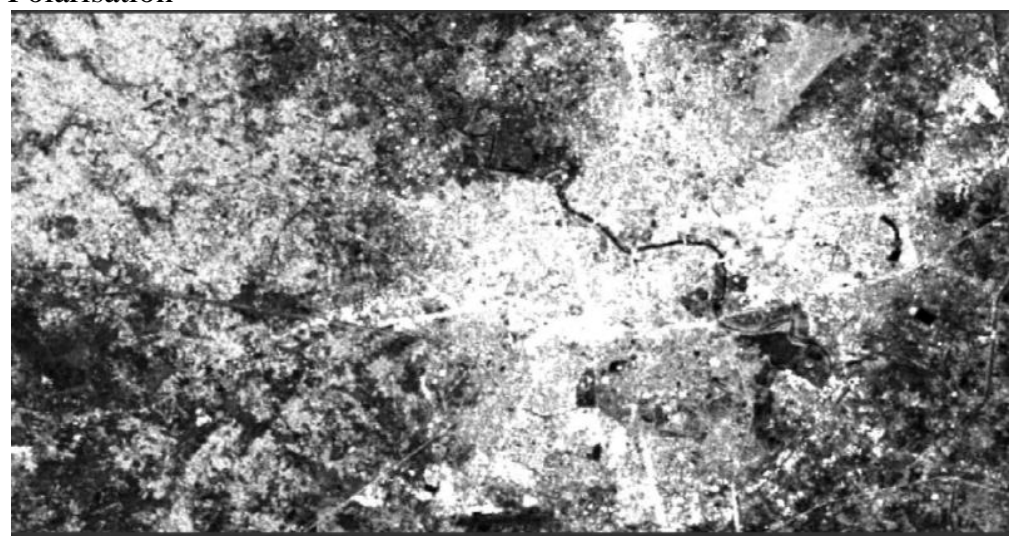




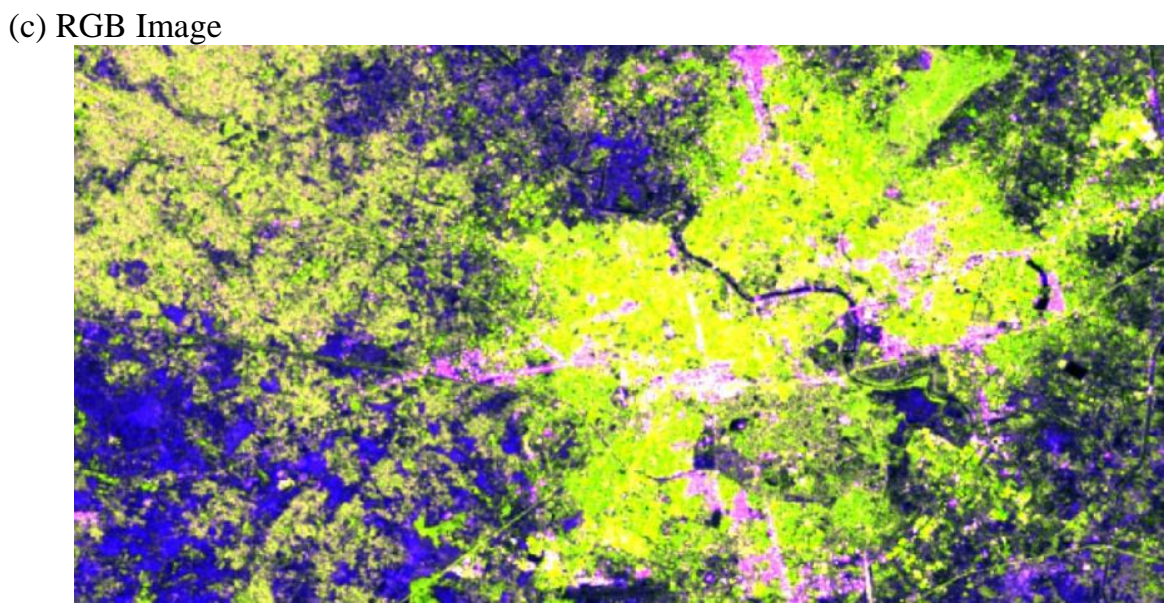

Table 17: Summary statistics of each feature

\begin{tabular}{llll}
\hline \multicolumn{1}{c}{ POLARISATION SPECIFICATION } & VH & VV \\
\hline RIVER & -21.89 & -16.59 & -18.83 \\
SEWAGE TREATMENT PLANT & -23.39 & -14.43 & \\
LAKE & -23.82 & 1.75 \\
BRIDGE & -13.07 & -4.10 & \\
ROAD & -18.08 & -8.62 \\
VEGETATION & -12.66 & -14.67 & \\
AGRICULTURE & -21.57 & -13.60 & \\
PARK & -21.22 & -6.25 & \\
SETTLEMENT & -10.72 & -17.14 & \\
BARREN LAND & -22.01 & 0.2 \\
RAILWAY STATION & -6.89 & \\
\hline
\end{tabular}

The study was performed with the help of two speckle filters (Boxcar \& Median). While performing the filters, all the details are set to default. Nothing changes manually. And different types of feature detection (natural and man-made) are performed and results clearly shown in output images with both the filters for dual-polarization. The river is clearly shown an in both polarisation and RGB. But the VH polarisation shown an image much clearer than VV polarisation. The radar images gave values above $-20 \mathrm{db}$ for the smooth features, like water bodies: - river, lake, sewage treatment plant, etc. and the $\mathrm{VH}$ dB values of each element showing values above $-20 \mathrm{db}$. In both the filters and for both the polarisation. Usually, man-made features are much clearer in a VV polarisation because they give back high back-scattered values and the Bridge is the main feature to connect two zones of Lucknow shown in an image. The boxcar filter results clearly shown that the values of the man-made feature are lower than the median filter, and the bridge can be easily seen in an RGB image with the white colour. The road is the main connectivity which joins two or more places at a location. And the roads are not much clearer in both the polarisation images but it can be seen in an RGB image, a star-like pattern is formed from outer towards the inner city. Due to smooth features, the back-scattered values of the road in a VH polarisation is closer to $-20 \mathrm{db}$. From the values, anyone can interpret the location of a road of the entire city. 
The vegetation is clearly shown in both the polarisation, the entire city is green. But the major vegetation can be shown in a north-east part of the Lucknow. And the back-scattered values of vegetation in $\mathrm{VH}$ polarisation is a little bit more than -10db and the results are shown for both the filters is closer to the standard value of vegetation. The VV polarisation in vegetation shown values below $-10 \mathrm{db}$. The agriculture and park values for both the filters in VH polarisation are more than $-20 \mathrm{db}$, which depicts the land of agriculture, or we can say that the crop is harvested that's why the values are more. The settlement is clearly shown in all around the image, the VV polarisation gives better performance for the settlement visibility and the settlement area. Lucknow is the main core city that's why outer areas settlement is joint with the core settlement, which makes a star-shaped pattern. Due to different roof materials, the settlements are not shown with a single colour but the yellow colour is the main prominent colour for showing settlements. Due to different roof materials the Railway stations are easy to find out because they gave backscattered values within $-8 \mathrm{db}$ for $\mathrm{VH}$ and 0-1 for VV polarisation.

\section{CONCLUSION}

The present study was performed to understand the application of freely available sentinel datasets for various applications with the help of pre-processing steps. The presence of speckle-noise has a key influence on SAR data processing. Most of the SAR images are underutilised due to the addition of unwanted backscatter or echoes in the image. So, unwanted noise or errors in the images are required to remove before any application. These can be done by applying a suitable filter to reduce the influence of the Noise or it can be performed by suppression of the additional noise. Various researchers have attempted in this regard to enhance the quality of the image. The work strengthens the approach for pre-processing of freely available dual-polarization synthetic aperture radar, understanding of the speckle noise, the noise reduction/suppression from the SAR datasets in VH and VV polarisations. The present study confirms that it is required to preserve the edge information for the wider application of the SAR images. The study operated on features like settlement, waterbodies, runways, bridge, sewage treatment plant and it was observed that VH polarized image are more helpful for the water studies and VV polarized image are more helpful for man-made objects like settlement, bridges, and runways etc. The processing of the GRD data pre-processing is much shorter and easier. The application of filters on GRD data shows that the filters behave as per the topography of the surface and backscatter values are being exhibited as per their surface properties. The work addresses the issues related to urban feature extraction, identification and feature selections. The work can be useful in the forthcoming data mining applications to identify the patterns in time-series datasets.

\section{REFERENCES}

Aher, S. P., and D. Ph (2014). Synthetic Aperture Radar in Indian Remote Sensing. INTERNATIONAL JOURNAL OF APPLIED IIformation Systems(IJAIS) 7 (2): 2012-15.

Bassuk, N. L, Blais Universite, A., Jean, M., Universite, C., Theoretical, L., Urban Politics, The City Book, et al. (2015). On Using Landscape Metrics for Landscape Similarity Search. Landscape and Urban Planning 117 (1): 1-12. https://doi.org/10.1038/srep11160.

Bernard, F., van Noordwijk, M., Luedeling, E., Villamor, G. B., Sileshi, G. W. and S. Namirembe (2014). Social Actors and Unsustainability of Agriculture. Current Opinion in Environmental Sustainability 6 (1): 155-61. https://doi.org/10.1016/j.cosust.2014.01.002. 
Betbeder, J., Rapinel, S., Corgne, S., Pottier, E., and L. Hubert-Moy (2015). TerraSAR-X Dual-Pol Time-Series for Mapping of Wetland Vegetation. ISPRS Journal of Photogrammetry and Remote Sensing 107: 90-98. https://doi.org/10.1016/ j.isprsjprs.2015.05.001.

Blaschke, T. (2010). Object Based Image Analysis for Remote Sensing. ISPRS Journal of Photogrammetry and Remote Sensing.

Blaschke, T, Werner,A., Storie, Ch. D., Storie, J., Hall, W. D., Alparone, L., Baronti, S., et al. (2019). Framework for Fusion of Ascending and Descending. Remote Sensing 11 (5): 1-14. https://doi.org/10.3390/rs11020201.

Canty, M. J., Nielsen, A. A., Conradsen, K. and H. Skriver (2020). Statistical Analysis of Changes in Sentinel-1 Time Series on the Google Earth Engine. Remote Sensing 12 (1): 116. https://doi.org/10.3390/RS12010046.

Dass, R, and N. Yadav (2020). Image Quality Assessment Parameters for Despeckling $\begin{array}{llllll}\text { Filters. } & \text { Procedia } & \text { Computer } & \text { Science } & 167 & \text { (2019): }\end{array}$ https://doi.org/10.1016/j.procs.2020.03.291.

Deepthi, R., Ravindranath, S., Ganesha Raj, K. (2018). Extraction of Urban Footprint of Bengaluru City Using. In The International Archives of the Photogrammetry, Remote Sensing and Spatial Information Sciences, Volume XLII-5, 2018 ISPRS TC V Mid-Term Symposium “Geospatial Technology - Pixel to People”, 20-23 November 2018, Dehradun, India, XLII (pp. 20-23). Dehradun.

Desclée, B., Bogaert, P. and P. Defourny (2006). Forest Change Detection by Statistical Object-Based Method. Remote Sensing of Environment 102 (1-2): 1-11.

Ghorbanian, A., Kakooei, M., Amani, M., Mahdavi, S., Mohammadzadeh, A. and M. Hasanlou (2020). Improved Land Cover Map of Iran Using Sentinel Imagery within Google Earth Engine and a Novel Automatic Workflow for Land Cover Classification Using Migrated Training Samples. ISPRS Journal of Photogrammetry and Remote Sensing 167 (July): 276-88. https://doi.org/10.1016/j.isprsjprs.2020.07.013.

Gibril, M. B. a., Bakar, S. a., Yao, K., Oludare Idrees, M. and B. Pradhan (2017). Fusion of RADARSAT-2 and Multispectral Optical Remote Sensing Data for LULC Extraction in a Tropical Agricultural Area. Geocarto International 32 (7): 735-48. https://doi.org/10.1080/10106049.2016.1170893.

Guo, L., Chen, L., Philip Chen, C. L. and J. Zhou (2018). Integrating Guided Filter into Fuzzy Clustering for Noisy Image Segmentation. Digital Signal Processing: A Review Journal 83: 235-48. https://doi.org/10.1016/j.dsp.2018.08.022.

Ji, K. and Y. Wu (2015). Scattering Mechanism Extraction by a Modified Cloude-Pottier Decomposition for Dual Polarization SAR. Remote Sensing 7 (6): 7447-70. https://doi.org/10.3390/rs70607447.

Jian, L., Yang, X., Zhou, Z., Zhou, K., Liu, K., Eichler, M., May, M., et al. (2020). Image Segmentation Based on Ultimate Levelings: From Attribute Filters to Machine Learning Strategies. Remote Sensing of Environment 175 (8-2019): 163671. https://doi.org/10.1016/j.isprsjprs.2008.07.005.

Knoepfle, W., Strunz, G. and A. Roth (1998). Mosaicing of Digital Elevation Models Derived by SAR Interferometry. IAPRS, “GIS-Between Visions and Applications” 32 (4): 306-13.

Kumar, D. (2020). Statistical Image Processing for Enhanced Scientific Analysis. In Smart Innovation, Systems and Technologies, 141 (pp. 1-11). Springer. https://doi.org/10.1007/ 
978-981-13-8406-6_1.

Kumar, D. and S. Shekhar (2016). Linear Gradient Analysis of Kinetic Temperature through Geostatistical Approach. Modeling Earth Systems and Environment 2 (3): 145. https://doi.org/10.1007/s40808-016-0198-3.

Lee, S., Cho, M., Lee, Ch., National, K. and S. Korea (2016). An Effective Gap Interpolation and Filtering (GIF) Method for Landsat 7 ETM+ SLC-off Data. Terrestrial, Atmospheric and Oceanic Sciences (TAO), no. September. https://doi.org/10.3319/TAO. 2016.07.18.02.

Li, L., Yang, J. and J. Wu (2019). A Method of Watershed Delineation for Flat Terrain Using Sentinel-2A Imagery and DEM: A Case Study of the Taihu Basin. ISPRS International Journal of Geo-Information 8 (12). https://doi.org/10.3390/ijgi8120528.

Li, Y., Wang, S., Zhao, Q. and G. Wang (2020). A New SAR Image Filter for Preserving $\begin{array}{lllll}\text { Speckle Statistical } & \text { Distribution. } & \text { Signal } & \text { Processing } & 176 .\end{array}$ https://doi.org/10.1016/j.sigpro.2020.107706.

Liu, N., Cao, Z., Cui, Z., Pi, Y. and S. Dang (2019). Multi-Scale Proposal Generation for Ship Detection in SAR Images. Remote Sensing 11 (5). https://doi.org/10.3390/rs11050526.

Liu, X., Shen, H., Yuan, Q., Zhang, L. and Q. Cheng (2016). A Novel Removal Method for Dense Stripes in Remote Sensing Images. ISPRS Annals of Photogrammetry, Remote Sensing and Spatial Information Sciences III-6 (July): 57-61. https://doi.org/10.5194/ isprsannals-iii-6-57-2016.

Loukanov, A., El Allaoui, N., Omor, A., Zahra Elmadani, F., Bouayad, K., Seiichiro, N., Lachowycz, K. et al. (2020). Effects of Neighborhood Building Density, Height, Greenspace, and Cleanliness on Indoor Environment and Health of Building Occupants. Environmental Research 106 (2): 213-22. https://doi.org/10.1016/ j.buildenv.2018.06.028.

Marpu, P. R., Neubert, M., Herold, H. and I. Niemeyer (2010). Enhanced Evaluation of Image Segmentation Results. Journal of Spatial Science 55 (1): 55-68. https://doi.org/10.1080/14498596.2010.487850.

Marshak, Ch., Simard, M. and M. Denbina (2019). Monitoring Forest Loss in ALOS/PALSAR Time-Series with Superpixels. Remote Sensing 11 (5). https://doi.org/10.3390/rs11050556.

Martí-Vidal, I., Vlemmings, W.H.T. and S. Muller (2016). Dual Differential Polarimetry. A Technique to Recover Polarimetric Information from Dual-Polarization Observations. Astronomy and Astrophysics 593. https://doi.org/10.1051/0004-6361/201628225.

Maxwell, S.M. and Craig, M.E. K. (2008). Use of Landsat ETM + SLC-off Segment-based Gap-filled Imagery For Crop Type Mapping, 1 1-12.

Meisen, P., Quéneudec, E., Yuan, M., Nara, A., Bothwell, J., Ramirez, L., Zink, R. et al. (2006). Overview of Renewable Energy Potential of India. Modeling Earth Systems and Environment 2 (10): 1-20. https://doi.org/10.1016/j.compenvurbsys.2015.03.002.

Mun, J., Jang, Y., Nam, Y. and J. Kim (2019). Edge-Enhancing Bi-Histogram Equalisation Using Guided Image Filter. Journal of Visual Communication and Image Representation 58: 688-700. https://doi.org/10.1016/j.jvcir.2018.12.037.

Periasamy, Sh. (2018). Significance of Dual Polarimetric Synthetic Aperture Radar in Biomass Retrieval: An Attempt on Sentinel-1. Remote Sensing of Environment 217 (4): $537-$ 49. https://doi.org/10.1016/j.rse.2018.09.003.

Romaguera, M., Suhyb Salama, Mhd., Krol, M. S., Hoekstra, A.Y., and Z. Su. (2014). Towards the Improvement of Blue Water Evapotranspiration Estimates by Combining 
Remote Sensing and Model Simulation. Remote Sensing, 7026-49. https://doi.org/10.3390/rs6087026.

Routray, S., Priya Malla, P., Kumar Sharma, S., Kumar Panda, S., and G. Palai. (2020). A New Image Denoising Framework Using Bilateral Filtering Based Non-Subsampled Shearlet Transform. Optik 216 (May): 164903. https://doi.org/10.1016/j.ijleo.2020.164903.

Roy, D. P., Kovalskyy, V., Zhang, H. K., Vermote, E. F., Yan, L., Kumar, S. S., and A. Egorov (2016). Characterization of Landsat-7 to Landsat-8 Reflective Wavelength and Normalized Difference Vegetation Index Continuity. Remote Sensing of Environment 185: 57-70. https://doi.org/10.1016/j.rse.2015.12.024.

Shastri, B. P, Haldar, D., and Sh. Mohan (2015). Temporal Monitoring of SAR Polarimetric Parameters and Scattering Mechanism for Major Kharif Crops and Surrounding Land Use. IJSRSET 1 (4): 416-24.

Singh, H., Sanchez, C., and G. Cristobal. (2020). Construction of Fused Image with Improved Depth-of-Field Based on Guided Co-Occurrence Filtering. Digital Signal Processing: A Review Journal 104: 102793. https://doi.org/10.1016/j.dsp.2020.102793.

Tukker, A. (2015). Product Services for a Resource-Efficient and Circular Economy - A Review. Journal of Cleaner Production. https://doi.org/10.1016/j.jclepro.2013.11.049.

Turkar, V., Deo, R., Rao, Y. S., Mohan, Sh., and A. Das (2012). Classification Accuracy of Multi-Frequency and Multi-Polarization SAR Images for Various Land Covers. IEEE Journal of Selected Topics in Applied Earth Observations and Remote Sensing 5 (3): 936-41. https://doi.org/10.1109/JSTARS.2012.2192915.

Turkar, V. and Y. S. Rao (2008). Classification of Polarimetric Synthetic Aperture Radar Images From SIR-C and ALOS PALSAR. 2008 International Conference of Recent Advances in Microwave Theory and Applications, MICROWAVE 2008, no. 12-2008: 43840. https://doi.org/10.1109/AMTA.2008.4763087.

Ullah, W., Noor, S. and A. Tariq (2018). The Development of a Basic Framework for the Sustainability of Residential Buildings in Pakistan. Sustainable Cities and Society 40 (1): 365-71. https://doi.org/10.1016/j.scs.2018.04.009.

Veci, L. and I. March (2015). SENTINEL-1 Toolbox SAR Basics Tutorial. Esa, no. 8: 1-20. http://sentinel1.s3.amazonaws.com/docs/S1TBX SAR Basics Tutorial.pdf.

Werner, A., Storie, Ch. D. and J. Storie (2014). Evaluating SAR-Optical Image Fusions for Urban LULC Classification in Vancouver Canada. Canadian Journal of Remote Sensing 40 (4): 278-90. https://doi.org/10.1080/07038992.2014.976700.

Yang, C. H., Kenduiywo, B. K. and U. Soergel (2016). Change Detection Based on Persistent Scatterer Interferometry - A New Method of Monitoring Building Changes. ISPRS Annals of the Photogrammetry, Remote Sensing and Spatial Information Sciences III (7): 12-19. https://doi.org/10.5194/isprsannals-III-7-243-2016.

Yang, H. Ch., Ming Chang, Ch. and P. L. Urban (2019). Automation of Fizzy Extraction Enabled by Inexpensive Open-Source Modules. Heliyon 5 (5): e01639. https://doi.org/10.1016/j.heliyon.2019.e01639. 